\title{
THE AMERICAN JOURNAL OF TROPICAL MEDICINE AND HYGIENE
}

\author{
(ISSN 0002-9637) \\ liditor, MCWILSON WARREN \\ 3088 Briarcliff Road, Suite Al Atlanta. Georgia 30329 \\ Telephone (404) 636-3621 FAX: (404) 633-5737 \\ Associate Editor, Allison Kitfield \\ Copy.Assistant Editor. THOMAS GRYCZAN
}

Editorial Board

RONALD ANTHONY

A. S. BENENSON

DONALD S. BURKe

Charles H. Calisher

AlLEN W. ChEEVER

DANIEL H. CONNOR

Joel M. DALRYMPLE

\author{
JAMES L. HARDY \\ DAVID J. JACOBUS \\ RODNEY C. JUNG \\ LLEWELLYN J. LEGTERS \\ Steven R. Meshnick \\ FRANKLIN A. NEVA
}

\author{
ROBERT E. SHOPE \\ Mette Strand \\ DiANE TAYLOR \\ BRYCE C. WALTON \\ THOMAS H. WELLER \\ THOMAS YUILL
}

The American Journal of Tropical Medicine and Hyiche is published monthly by the American Society of Tropical Medicine and Hygiene and consists of two complete scquentially numbered volumes each calendar year.

Correspondenc' conc'rning business matters, subscriptions, and memberships should be addressed to The American Society of Tropical Medicine and Hygiene, 8000 Westpark Drive, Suite 130, McLean. VA 22102: telephone (703) 790-1745. FAX (703) 790-9063.

Mamuscripts of aticles for publication and books for review should be sent to the Editor.

The subscription price for the pair of volumes is $\$ 105.00$ per year in the USA, $\$ 110.00$ per year in Canada and Mexico. and $\$ 170.00$ elsewhere. The price of single copies, when available, is $\$ 17.00$ in the USA and $\$ 18.00$ elsewhere. Second class postage paid at McLean. VA with an additional office at Lawrence. KS.

New subscriptions and renewals are entered to begin with the January issue of the current year. Should any issue of the current year be out of print at the time the subscription order is received. the pro rata value of such numbers will be refunded.

Subscriptions should be renewed promptly: The publisher cannot guarantee to supply back issues on belated renewals.

Change of address. POSTMASTER: Send address changes to the American Society of Tropical Medicine and Hygiene. 8000 Westpark Drive, Suite 130. McLean. VA 22102. Members of the Society should notify the Secretary of any change in address. All other subscribers should notify the publisher 60 davs in advance. Copies of the Joumal that are undeliverable because of an incorrect address will be destroyed. Duplicates of such copies may be obtained (if available) from the publisher at the regular price of single issues.

\section{OFFICERS OF THE}

\section{American Society of Tropical Medicine and Hygiene}

\section{President}

DONALD J. Krogstad

President-lilect

DANIEL COLLEY

Scicntific Program Chairman

Thomas P. MONath

Serretary-Treasurer.

Peter Weller

Infectious Discase. DA-617

Beth Israel Hospital

330 Brookline Avenue

Boston. MA 02215-5491

Eiditor. Tropical Medicine

and Hygiene Nens

KARL A. WESTERN councilors

DiCKSON DESPOMMIER

Stephanie L. James

STEPHEN HOFFMAN

REBECA RiCO-HESS

Carlos Campbell

ELAINE JONG

MICHELE BARRY

HARRISON SPENCER
Term Expires

1992

1992

Printed by Allen Press, Inc.: 1041 New Hampshire Strect: Lawrence. KS 66044

Statements and opinions expressed in publications of the American Society of Tropical Medicine and Hygiene or in presentations given during its regular meetings are those of the author(s) and do not necessarily reflect the official position of the American Society of Tropical Medicine and Hygiene, the editors, or the organizations with which the authors are affiliated. The Editor(s), publisher, and Society disclaim any responsibility or liability for such material and do not guarantee, warrant. or endorse any product or service mentioned, nor do they guarantee any claim made b: the manufacturer of such product or service. Official positions of the Society are established only by its Council. 


\section{THE AMERICAN JOURNAL OF TROPICAL MEDICINE AND HYGIENE

\section{CONTENTS}

\author{
Boutonneuse Fever - 78 \\ Capillariasis - 10 \\ Chagas' Disease - 20 \\ Chikungunya Virus - 98 \\ Giardiasis -13 \\ Japanese B Encephalitis - 61 \\ Leishmaniasis - 47, 87, 117 \\ Lyme Disease - 55
}

\author{
Lymphocytic \\ Choriomeningitis - 27 \\ Malaria - 1, 41, 108, 112 \\ Paragonimiasis - 104 \\ Plague - 92 \\ Q Fever - 35 \\ Schistosomiasis -6 \\ Trichomonas vaginalis -70
}

In this issue

\section{TRAVEL MEDICINE}

The efficacy of halofantrine in the treatment of acute malaria in nonimmune travelers-Thomas Weinke, Thomas Loscher, Klaus Fleischer, Harald Kretschmer, Hans D. Pohle, Bernd Kohler, Thomas Schlunk, Ralf Clemens, and Hans L. Bock

Schistosomiasis and the Dogon country (Mali)-M. Corachan, L. Ruiz, M. E. Valls, and J. Gascon

Intestinal capillariasis (Capillaria philippinensis) acquired in Indonesia: a case report-Guido Chichino, Anna Maria Bernuzzi, Antonella Bruno, Claudia Cevini, Chiara Atzori, Antonello Malfitano, and Massimo Scaglia

\section{EPIDEMIOLOGY}

Epidemiology of giardiasis in Wisconsin: increasing incidence of reported cases and unexplained seasonal trends-David G. Addiss, Jeffrey P. Davis, Jacquelin M. Roberts, and Eric E. Mast

Vectorial transmission of Trypanosoma cruzi: an experimental field study with susceptible and immunized hosts-S. S. Catala, D. E. Gorla, and M. A. Basombrio

Lymphocytic choriomeningitis virus infection and house mouse (Mus musculus) distribution in urban Baltimore-James E. Childs, Gregory E. Glass, George W. Korch, Thomas G. Ksiazek, and James W. LeDuc

A cluster of Coxiella burnetii infections associated with exposure to vaccinated goats and their unpasteurized dairy products-Daniel B. Fishbein and Didier Raoult

Ookinete rates in Afrotropical anopheline mosquitoes as a measure of human malaria infectiousness - John C. Beier, Robert S. Copeland, Ramadhan Mtalib, and Jefferson A. Vaughan

Epidemiologic investigation of an outbreak of cutaneous leishmaniasis in a defined geographic focus of transmission-Jose L. Sanchez, Benedict M. Diniega, James W. Small, Richard N. Miller, Jose M. Andujar, Peter J. Weina, Phillip G. Lawyer, W. Ripley Ballou, and James K. Lovelace

Clustering of host-seeking nymphal deer ticks (Ixodes dammini) infected by Lyme disease spirochetes (Borrelia burgdorferi)-Sam R. Telford III, Sandy S. Urioste, and Andrew Spielman 


\section{MOLECULAR/BASIC BIOLOGY}

A new genotype of Japanese encephalitis virus from Indonesia-Woan-Ru Chen, Rebeca RicoHesse, and Robert B. Tesh

Characterization of the heat-shock response of Trichomonas vaginalis-Sara R. Davis and William B. Lushbaugh

Antigenic diversity of Rickettsia conorii-David H. Walker, Qing-huai Liu, Xue-jie Yu, Han Li, Catherine Taylor, and Hui-min Feng

Nucleoside transporters in Leishmania major: diversity in adenosine transporter expression or function in different strains-Hans P. Baer, Vincent Serignese, Patrick O. J. Ogbunude, and Maud Dzimiri

\section{IMMUNOLOGY/VACCINES}

Failure of intragastrically administered Yersinia pestis capsular antigen to protect mice against challenge with virulent plague: suppression of fraction 1-specific antibody response-Rex E. Thomas, Warren J. Simpson, Linda L. Perry, and Tom G. Schwan

Limited potential for mosquito transmission of a live, attenuated chikungunya virus vaccineMichael J. Turell and Frank J. Malinoski

Parasite-specific IgE and IgG levels in the serum and pleural effusion of paragonimiasis westermani patients-Teruaki Ikeda, Yosaburo Oikawa, Makoto Owhashi, and Yukifumi Nawa

\section{DRUG STUDIES}

Quinine with tetracycline for the treatment of drug-resistant falciparum malaria in ThailandGeorge Watt, Lersan Loesuttivibool, G. Dennis Shanks, Ellen F. Boudreau, Arthur E. Brown, Katchrinnee Pavanand, H. Kyle Webster, and Suwit Wechgritaya

Emergence of multidrug-resistant Plasmodium falciparum in Thailand: in vitro trackingChansuda Wongsrichanalai, H. Kyle Webster, Theera Wimonwattrawatee, Prasit Sookto, Niphon Chuanak, Krongthong Thimasarn, and W. H. Wernsdorfer

Drug resistance in leishmaniasis: its implication in systemic chemotherapy of cutaneous and mucocutaneous disease-Max Grogl, Tina N. Thomason, and Eileen D. Franke

Number 6 (June) of Volume 46 was mailed to subscribers on 30 June 1992 



\title{
THE EFFICACY OF HALOFANTRINE IN THE TREATMENT OF ACUTE MALARIA IN NONIMMUNE TRAVELERS
}

\author{
THOMAS WEINKE, THOMAS LOSCHER, KLAUS FLEISCHER, HARALD \\ KRETSCHMER, HANS D. POHLE, BERND KOHLER, THOMAS SCHLUNK, RALF \\ CLEMENS, AND HANS L. BOCK \\ Universitatsklinikum Rudolf Virchow, II Medizinische Klinik, Berlin, Germany; Abteilung fur \\ Infektions und Tropenmedizin der Universitat, Munchen, Germany; Missionsarztliche Klinik, \\ Tropenmedizin, Wurzburg, Germany; Tropenklinik Paul-Lechler-Krankenhaus, Tubingen, Germany; \\ Smith Kline Beecham, Klinische Forschung, Munchen, Germany
}

\begin{abstract}
A multicenter prospective trial was performed to investigate the efficacy and the tolerability of halofantrine in nonimmune patients with malaria imported from areas with drug-resistant falciparum parasites (mainly Africa). Forty-five of the 74 subjects were treated with a one-day regimen $(3 \times 500 \mathrm{mg})$ of halofantrine, and the other 29 received the same regimen with an additional treatment on day 7 . In the second group, a $100 \%$ efficacy rate was demonstrated, but in the group receiving the one-day regimen, four recrudescences were observed in patients with falciparum malaria. Only five mild adverse reactions were seen, which disappeared spontaneously after the end of the treatment. We conclude that halofantrine is highly effective in curing malaria in nonimmune subjects. The treatment scheme for such persons should include an additional treatment on day 7 for nonimmune individuals. This drug was well tolerated in our patients, indicating that halofantrine will be useful in the treatment of multidrug-resistant malaria in nonimmune persons.
\end{abstract}

The spread of multi-resistant Plasmodium falciparum strains to many countries where malaria transmission occurs poses a considerable challenge in the treatment of infected patients. ${ }^{1}$ Furthermore, severe side effects of other established antimalarial drugs such as pyrimethamine-sulfadoxine (Fansidar ${ }^{\circledR}$ ) or amodiaquine restrict their use for prophylaxis or treatment. ${ }^{2-5}$ One of the newer drugs, mefloquine, has been shown to produce moderate to severe neuropsychiatric reactions with a frequency of 1 in 215 after therapeutic use ${ }^{6}$ reduced in vitro sensitivity has also been demonstrated with this drug. ${ }^{7}$ Therefore, new drugs that are efficacious and safe are urgently needed.

Halofantrine, a phenanthrene methanol, is such a new antimalarial drug, and it has been shown to be efficacious in semi-immune patients in various endemic areas. ${ }^{8-13}$ Data are scanty on nonimmune travelers who have contracted malaria during short term stays in the tropics and their treatment with halofantrine. ${ }^{14}$ In semi-immune persons, a one-day treatment produced excellent results, but recrudescences were reported in nonimmune patients. ${ }^{15}$ The current study was undertaken to investigate the efficacy and tol- erability of halofantrine hydrochloride in nonimmune patients, and to evaluate the need for a regimen with a repetitive dose after one week.

\section{PATIENTS AND METHODS}

This multicenter trial was carried out prospectively in four hospitals in Germany. Patients who returned from a stay in the tropics were screened and recruited if they met the following criteria: 1) they had parasitologic evidence of parasites in the blood with clinical symptoms of malaria, 2) they were older than 18 years of age and younger than 65 years of age, and 3) they were nonimmune white individuals living usually in Central Europe, or if the patient is of African/Asian origin, they must have stayed more than one year outside endemic areas. Written informed consent for participation in the study was obtained from all patients.

Parasite densities were calculated by counting asexual parasites against 5,000 red blood cells on Giemsa-stained thin blood films, or against 200 white blood cells on thick blood films when the parasitemia was $<0.1 \%$.

Exclusion criteria were 1) severe or compli- 
cated malaria (e.g., renal failure, severe hypotension, central nervous system disorders, vomiting, fever $>41^{\circ} \mathrm{C}$ ) or a parasite count $>500,000 / \mu 1$, 2) being pregnant or nursing, 3) body weight $<$ $40 \mathrm{~kg}$, and 4) concomitant antimalarial treatment.

Forty-five patients were treated orally with halofantrine hydrochloride $(3 \times 500 \mathrm{mg}$ tablets $)$ within a 12 -hr period (group 1). The other 29 patients were given the same treatment regimen on day 0 and an additional treatment on day 7 (group 2). No differences could be observed between the two groups concerning travel destinations. In those with $P$. vivax malaria, a standard course of primaquine was given after the treatment with halofantrine. Although $80 \mathrm{pa}-$ tients were enrolled in the study, six were not available for followup examinations, and a judgment of drug efficacy in these patients was not possible. The data from these six patients were included only in the evaluation of drug tolerability.

Efficacy and tolerability evaluations included hematologic examinations (hemoglobin level and white blood cell and platelet counts), clinical biochemical tests (levels of creatinine, blood urea nitrogen, bilirubin, liver transaminases and alkaline phosphatase, and serum electrolytes and glucose), urinalysis (glucose and protein levels), recording of body temperature, and parasite count (parasite density). Hematologic and biochemical values were determined on days $1-5,7,14,21$, and 28 , urinalysis was performed once a week, and temperatures were recorded twice a day. Parasite counts were obtained before treatment, twice a day until blood smears were negative, and on days $5,7,14,21$, and 28 . Clinical investigations were carried out on days $1-5,7,14,21$, and 28 . Thus, efficacy could be determined with the following parameters: cure rate, parasite clearance time (hr), fever clearance time (hr), and recrudescence rate. Drug tolerability was measured by determination of the frequency and severity of adverse reactions.

\section{RESULTS}

The 74 fully compliant subjects (55 men and 19 women) had a mean age of 35.5 years (age range 23-61) and a mean body weight of 72.9 $\mathrm{kg}$ (range 52-101.8). Sixty-two of the 74 patients $(83.8 \%)$ were white and lived in Central Europe. Ten (13.5\%) were of African origin and two (2.7\%) were of Asian origin, but all had lived in Germany for a period of more than one year.

Plasmodium falciparum was detected in 50 patients and $P$. vivax in 20 patients; in four patients, the Plasmodium species could not be classified because of very low parasitemias and identification of parasites on thick smears only. The mean pretreatment parasite count was $40,350 /$ $\mu \mathrm{l}$ and the parasite density ranged from $<5,000 /$ $\mu$ l to $250,000 / \mu \mathrm{l}$ (Table 1). The patients had contracted their malaria infections in sub-Saharan Africa (78\%), South America (6\%), the Indian subcontinent (6\%), and southeast Asia (10\%). Malaria chemoprophylaxis was used by $37(50 \%)$ of the 74 travelers, and consisted mainly of chloroquine $(n=21)$ or chloroquine plus proguanil $(n=9) ; 37(50 \%)$ patients did not use any chemoprophylactic agent.

Pretreatment clinical symptoms consisted of fever $(n=71,95.9 \%)$, headache $(n=64,87 \%)$, dizziness $(n=50,68 \%)$, chills/rigors $(n=38$, $51 \%)$, nausea $(n=45,61 \%)$, diarrhea $(n=8$, $11 \%)$, and abdominal pain $(n=13,18 \%)$. The median fever clearance time was $53 \mathrm{hr}$ (range 4$185)$ and was shorter than the parasite clearance time of $65 \mathrm{hr}$ (range 18-225). Clearance times were slightly longer in those with $P$. falciparum infections (fever clearance time $=49 \mathrm{hr}$ and parasite clearance time $=66 \mathrm{hr}$ ) compared with those with $P$. vivax infections $(42$ and $62.5 \mathrm{hr}$, respectively), but these differences were not statistically significant.

In all patients, clinical symptoms of malaria disappeared and parasites could no longer be detected on day 14 (Table 2). Subsequently, four infections recrudesced in group 1 (treatment on day 0 only) on days 14, 22 (two patients), and 28 , respectively, indicating that four $(15.4 \%)$ of 26 patients in group 1 with $P$. falciparum infections recrudesced. In group 2 (treatment on days 0 and 7), none of the 24 patients with P. falciparum malaria recrudesced. Although this difference was not statistically significant, a clinically relevant trend was apparent. The four patients whose infections recrudesced were white individuals; three of them had used a chemoprophylactic (chloroquine), while the fourth patient had not used any chemoprophylactic. Their body weights did not differ significantly from the successfully treated group, and their initial parasite counts were only slightly lower $(3,500,9,500$, 10,500 , and $48,000 / \mu 1$, respectively). All four patients had returned from tropical Africa. A def- 
TABLE 1

Parasitemia in the 74 malaria patients in this study

\begin{tabular}{lc}
\hline \multicolumn{1}{c}{ Parasites $/ \mu \mathrm{l}$} & No. (\%) \\
\hline$<5,000$ & $9(12.2)$ \\
$5,000-50,000$ & $48(64.9)$ \\
$50,000-100,000$ & $8(10.8)$ \\
$100,000-250,000$ & $2(2.7)$ \\
$>250,000$ & $3(4.1)$ \\
Not done & $4(5.4)$ \\
Total & $74(100.0)$ \\
\hline
\end{tabular}

inite cure of these recrudescences was possible by treatment with quinine or mefloquine. No recrudescences were observed in any patients in both groups with $P$. vivax malaria.

Clinical tolerance to treatment with halofantrine was good, with only six patients reporting side effects. One patient each complained of diarrhea, itching, nausea, skin rash, fever, and angioneurotic (Quincke) edema. All reactions were graded as mild and disappeared spontaneously a few days after the end of the halofantrine treatment. Five of these six adverse reactions were confined to those who had a one-day therapy regimen. Only angioneurotic edema occurred in a patient who received two days of therapy; concomitant to falciparum malaria, the same patient had Dengue fever. Treatment of this patient with a second dose of halofantrine on day 7 did not produce any adverse reaction. Therefore, it is more likely that the angioneurotic (Quincke) edema was a reaction that occurred after the onset of Dengue fever. Thus, five $(6.25 \%)$ of 80 patients developed mild, reversible side effects. Hematologic and clinical biochemical test results remained within the normal limits after treatment in all patients.

In addition, two patients developed neurologic symptoms within the 28-day followup period that were judged to be unrelated to the intake of halofantrine. A 32-year-old woman who received halofantrine on day 0 complained of weakness in her legs on day 19 post-treatment. She was hospitalized and diagnosed as having GuillainBarre syndrome (with typical cerebrospinal fluid findings) of unknown etiology. A 50-year-old man who received halofantrine on days 0 and 7 developed viral encephalitis with disorientation and speech disturbance 23 days after initiating treatment. He had a significant influenza $A$ virus titer, indicating that influenza $A$ virus was the probable cause of his encephalitis. Both patients improved spontaneously.

\section{DISCUSSION}

The role of antimalarial drugs in the control of malaria has undergone major revisions in recent years with the increase of drug resistance in Plasmodium falciparum. Thirty years ago, the sensitivity of the parasite was the norm. Today, resistance to chloroquine and other alternative compounds is dominant and still spreading. ${ }^{1}$ This has encouraged the development of new drugs. The Walter Reed Army Institute of Research has identified various new antimalarial drugs, including halofantrine in the 1970 s. ${ }^{16.17}$ This compound, a phenanthrene methanol, proved to be more efficacious and less toxic than other new compounds, and has undergone extensive evaluation since that time. ${ }^{16.18}$ It has proved to be effective in the treatment of drug-resistant strains of $P$. falciparum in semi-immune patients in various geographic localities. ${ }^{8-13}$

In this study, we show that halofantrine is $100 \%$ effective in the treatment of malaria in nonimmune patients if a regimen including a second treatment on day 7 is applied. A similar experience was reported by Bernard and others, ${ }^{14}$ who successfully treated 59 patients from tropical Africa with a two-day course of halofantrine on days 1 and 8 . The one-day dosing regimen $(3 \times$ $500 \mathrm{mg}$ in group 1) in our study seems to be less effective, since four (15.4\%) of 26 patients with $P$. falciparum infections recrudesced. Our results

TABLE 2

Parasite clearance and recovery from fever in the 74 malaria patients

\begin{tabular}{|c|c|c|c|c|c|}
\hline & \multicolumn{5}{|c|}{ Day } \\
\hline & 0 & 2 & 5 & 7 & 14 \\
\hline No. (\%) of parasitemic patients & $74(100)$ & $56(76)$ & $2(3)$ & $1(1)$ & $0(0)$ \\
\hline Median parasitemia (parasites $/ \mu \mathrm{l}$ ) & 40,350 & 2,000 & 0 & 0 & 0 \\
\hline Parasite density $/ \mu$ l (range) & $50-500,000$ & $50-20,000$ & $<50-2,250$ & $<50$ & 0 \\
\hline No. $(\%)$ of patients with fever $\left(>38^{\circ} \mathrm{C}\right)$ & $71(96)$ & $25(34)$ & $3(4)$ & $1(1)$ & $0(0)$ \\
\hline
\end{tabular}


indicate that the one-day dosing regimen, which is extremely effective in semi-immune persons, is not sufficient in nonimmune travelers. Thus, the manufacturer of halofantrine (Smith Kline Beecham, Munchen, Germany) has taken this into consideration and recommends an adult equivalent dose of $3 \times 500 \mathrm{mg}$ on days 0 and 7 . Because of the relatively late recrudescences (days 14,22 , and 28) seen in four patients following treatment with halofantrine, it is essential to follow-up patients for at least one month before a cure may be confirmed. In the interest of the nonimmune patient, a treatment on day 0 only can no longer can be justified. These findings confirm the preliminary data of Coulaud and others, ${ }^{15}$ who observed three recrudescences in 11 nonimmune individuals and recommended a second treatment on day 14 . Since attempts to use a single dose regimen were unsuccessful, ${ }^{19}$ we chose the three-dose regimen used in this study.

In general, halofantrine was well tolerated by our patients. We saw no significant effects on hematologic or biochemical parameters, and the few mild reactions observed disappeared spontaneously. A judgment about the frequency of rare severe drug reactions in the order of $1 / 1,000$ or less is usually made only after the drug has been licensed for a few years, as shown by the experience with pyrimethamine-sulfadoxine (Fansidar $\left.^{\circledR}\right)^{2}$ or mefloquine. ${ }^{6.20 .21}$ Therefore, a definitive statement concerning rare side effects after treatment with halofantrine cannot be made, but in view of its relatively short half-life of 1-2 days, ${ }^{22 .}{ }^{23}$ (compared with 25 days for mefloquine), long-lasting side effects are not very probable. Another advantage of its short half-life is that this can be of importance in reducing the selection of less susceptible parasites, thereby delaying the emergence of halofantrine resistance. (In this regard, halofantrine will not be used for general chemoprophylaxis, but only as a treatment drug.)

One problem encountered in using halofantrine is that it is poorly soluble in water, which probably explains the wide variation in bioavailability in different subjects. ${ }^{22}$ This may also account for the recrudescences we observed, although we did not measure drug levels in the sera of our patients. It was possible to exclude reinfection in our patients, since all of them stayed in Germany during the followup period. The recommendation that patients should take halofantrine with a fatty meal to increase absorption is of limited practicability, since patients with clinical signs of malaria usually do not like to eat fatty food. Since no intravenous formulation of this drug currently exists, this drug has been restricted for use only in mild-to-moderate malaria cases.

Half of our patients took a chemoprophylaxis with chloroquine, and most of these cases originated from sub-Saharan Africa, where chloroquine resistance is well established. ${ }^{\prime}$ Our findings indicate that halofantrine is effective in the treatment of chloroquine-resistant $P$. falciparum malaria, as well as in $P$. vivax infections in nonimmune subjects. Given the finding that this drug was both efficacious and well-tolerated, its role in the treatment of multidrug-resistant falciparum malaria appears promising.

Authors' addresses: Thomas Weinke and Hans D. Pohle, Universitatsklinikum Rudolf Virchow, II Medizinische Klinik, Berlin, Germany (Dr. Weinke's present address: Universitatsklinikum Steglitz, Freie Universitat Berlin, Medizinische Klinik, Hindenburgdamm 30, 1000 Berlin 45, Germany). Thomas Loscher, Abteilung fur Infektions und Tropenmedizin der Universitat, Munchen, Germany. Klaus Fleischer and Bernd Kohler, Missionsarztliche Klinik, Tropenmedizin, Wurzburg, Germany. Harald Kretschmer and Thomas Schlunk, Tropenklinik Paul-Lechler-Krankenhaus, Tubingen, Germany. Ralf Clemens and Hans L. Bock, Smith Kline Beecham, Klinische Forschung, Munchen, Germany.

\section{REFERENCES}

1. Moran JS, Bernard KW, 1989. The spread of chloroquine-resistant malaria in Africa. Implications for travelers. JAMA 262: 245-248.

2. Miller KD, Lobel HO, Satriale RF, Kuritsky JN, Stern R, Campbell CC, 1986. Severe cutaneous reactions among American travelers using pyrimethamine-sulfadoxine (Fansidar ${ }^{\circledR}$ ) for malaria prophylaxis. Am J Trop Med Hyg 35: 451458.

3. Neftel KA, Woodtly W, Schmid M, Frick PG, Fehr J, 1986. Amodiaquine induced agranulocytosis and liver damage. $\mathrm{Br}$ Med J 222: 721-723.

4. Phillips-Howard PA, West LJ, 1990. Serious adverse drug reactions to pyrimethamine-sulfadoxine, pyrimethamine-dapsone, and to amodiaquine in Britain. $J R$ Soc Med $93: 82-85$.

5. Steffen R, Heusser R, Machler R, Bruppacher R, Naef U, Chen D, Hofmann AM, Somaini B, 1990. Malaria chemoprophylaxis among European tourists in tropical Africa: use, adverse reactions, and efficacy. Bull World Health Organ 68: 313-322.

6. Weinke T, Trautmann M, Held T, Weber G, Eichenlaub D, Fleischer K, Kern W, Pohle HD, 
1991. Neuropsychiatric side effects after the use of mefloquine. Am J Trop Med Hyg 45: 86-91.

7. Oduola AMJ, Milhous WK, Salako LA, Walker O, Desjardins RE, 1987. Reduced in-vitro susceptibility to mefloquine in West African isolates of Plasmodium falciparum. Lancet ii: 1304-1305.

8. Chitchang S, Wongteptien S, 1989. A clinical trial of halofantrine in acute uncomplicated malaria in Thai soldiers. Parasitol Today 5 (suppl): 21 26.

9. Maisonneuve H, Joly F, John M, Carles G, Rossignol JF, 1988. Efficacite de l'halofantrine dans le paludisme a Plasmodium falciparum ou a Plasmodium vivax. Dans une zone de resistance (Guyane francaise). Presse Med 17: 99-102.

10. Parkinson D, Balmer V, Ajdukiewicz A, Korinohowa A, Kere N, 1989. The effectiveness of halofantrine for the treatment of acute malaria in adults in the Solomon Islands. Parasitol Today 5 (suppl): 27-35.

11. Rab SM, Sheikhani MS, Mahmoud SA, Jaffary SIH, 1989. The efficacy of halofantrine hydrochloride in acute malaria: a study of 74 patients from Karachi, Pakistan. Parasitol Today 5 (suppl): 37-44.

12. Watkins WM, Oloo JA, Lury JD, Mosoba M, Kariuki D, Mjomba M, Koech DK, Gilles HM, 1988. Efficacy of multiple-dose halofantrine in treatment of chloroquine-resistant falciparum malaria in children in Kenya. Lancet ii: 247-249.

13. Wirima J, Khoromana C, Molyneux ME, Gilles HM, 1988. Clinical trials with halofantrine hydrochloride in Malawi. Lancet ii: $250-251$.

14. Bernard J, Sarrouy J, Dupasquier I, Lesbordes JL, Gimenez M, Geffray L, Becker JM, Molinas JM, Jourdan G, 1990. Traitement du paludisme d'importation a Plasmodium falciparum par l'halofantrine. Med Trop (Paris) 50: 167-171.

15. Coulaud JP, Le Bras J, Matheron S, Moriniere B,
Saimot AG, Rossignol JF, 1986. Treatment of imported cases of falciparum malaria in France with halofantrine. Trans $R$ Soc Trop Med Hyg 80: 615-616.

16. Rinehart J, Arnold J, Canfield CJ, 1976. Evaluation of two phenanthrenemethanols for antimalarial activity in man: WR 122455 and WR 171 669. Am J Trop Med Hyg 25: 769-774.

17. Schmidt LH, Crosby R, Rasco J, Vaughan D, 1972. Antimalarial activities of various 9-phenanthrenemethanols with special attention to WR-122 455 and WR-171 669. Antimicrob Agents Chemother 14: 292-314.

18. Cosgriff TM, Boudreau EF, Pamplin CL, Doberstyn EB, Desjardins RE, Canfield CJ, 1982. Evaluation of the antimalarial activity of the phenanthrenemethanol halofantrine (WR 171, 669). Am J Trop Med Hyg 31: 1075-1079.

19. Boudreau EF, Pang LW, Dixon KE, Webster HK, Pavanand K, Tosingha L, Somutsakorn P, Canfield CJ, 1988. Malaria: treatment efficacy of halofantrine (WR 171 669) in initial field trials in Thailand. Bull World Health Organ 66: 227235.

20. Rouveix B, Bricaire F, Michon C, Franssen G, Lebras J, Bernard J, Ajana F, Vienne JL, 1989. Mefloquine and an acute brain syndrome. Ann Intern Med 110: 577-578.

21. Harinasuta T, Bunnag D, Wernsdorfer WH, 1983. A phase II clinical trial of mefloquine in patients with chloroquine-resistant falciparum malaria in Thailand. Bull World Health Organ 61: 299305.

22. Broom C, 1989. Human pharmacokinetics of halofantrine hydrochloride. Parasitol Today 5 (suppl): 15-20.

23. Schuster BG, Canfield CJ, 1989. Preclinical studies with halofantrine. Parasitol Today 5 (suppl): 3-13. 